\title{
A Multitracer Dopaminergic PET Study of Young-Onset Parkinsonian Patients With and Without Parkin Gene Mutations
}

Maria-João Ribeiro ${ }^{1}$, Stéphane Thobois ${ }^{2}$, Ebba Lohmann ${ }^{3-5}$, Sophie Tezenas du Montcel ${ }^{6,7}$, Suzanne Lesage ${ }^{3,5}$, Antoine Pelissolo ${ }^{8}$, Bruno Dubois ${ }^{3,5,9}$, Luc Mallet $^{10}$, Pierre Pollak ${ }^{11}$, Yves Agid ${ }^{3-5,12}$, Emmanuel Broussolle $^{2}$, Alexis Brice ${ }^{3-5,13}$, Philippe Remy ${ }^{14,15}$, and The French Parkinson's Disease Genetics Study Group

${ }^{I}$ CEA, I2BM, Service Hospitalier Frédéric Joliot, Orsay, France; ${ }^{2}$ University of Lyon; Hospices Civils de Lyon, Neurological Hospital, Lyon, France; ${ }^{3}$ INSERM, Paris, France; ${ }^{4}$ Department of the Nervous System Disorders, AP-HP, Pitié-Salpêtrière Hospital, Paris, France, ${ }^{5}$ UPMC University of Paris, Paris, France; ${ }^{6}$ Unit of de Biostatistics and Medical Information and Unit of Medical Research, AP-HP, Pitié-Salpêtrière Hospital, Paris, France, ${ }^{7}$ Modelisation in Clinical Research, UPMC University of Paris, Paris, France; ${ }^{8}$ Department of Psychiatry, AP-HP, Pitié-Salpêtrière Hospital, Paris, France; ${ }^{9}$ Centre de Référence sur la Maladie de Pick, AP-HP, Pitié-Salpêtrière Hospital, Paris, France; ${ }^{10}$ Behaviour, Emotion and Basal Ganglia, Center of Clinical Investigation, INSERM Avenir Group, Paris, France; ${ }^{11}$ Department of Clinical and Biological Neurosciences, University Hospital of Grenoble, Grenoble, France; ${ }^{12}$ Clinical Investigation Center, AP-HP, Pitié-Salpêtrière Hospital, Paris, France; ${ }^{13}$ Department of Genetics and Cytogenetics, AP-HP, Pitié-Salpêtrière Hospital, Paris, France; ${ }^{14}$ CEA, I2BM, MIRCEN, URA CEA-CNRS 2210, Orsay, France; and ${ }^{15} \mathrm{CHU}$ Henri Mondor, AP-HP and Faculté de Médecine Paris 12, Créteil, France

The impact of parkin gene mutations on nigrostriatal dopaminergic degeneration is not well established. The purpose of this study was to characterize by PET using ${ }^{18} \mathrm{~F}$-fluoro-L-3,4dihydroxyphenylalanine ( ${ }^{18} \mathrm{~F}$-fluoro-L-DOPA), ${ }^{11} \mathrm{C}-\mathrm{PE} 2 \mathrm{I}$, and ${ }^{11} \mathrm{C}$-raclopride the pattern of dopaminergic lesions in young-onset Parkinson disease (YOPD) patients with or without mutations of the parkin gene and to correlate the clinical and neuropsychologic characteristics of these patients with PET results. Methods: A total of 35 YOPD patients were enrolled (16 with parkin mutation, 19 without). The uptake constant $\left(\mathrm{K}_{\mathrm{i}}\right)$ of ${ }^{18} \mathrm{~F}$-fluoroL-DOPA and the binding potential (BP) of ${ }^{11} \mathrm{C}-\mathrm{PE} 2 \mathrm{I}(\mathrm{BP}$ DAT $)$ and of ${ }^{11} \mathrm{C}$-raclopride $\left(\mathrm{BP}_{\mathrm{D} 2}\right)$ were calculated in the striatum. Comparisons were made between the 2 groups of YOPD and between controls and patients. For each radiotracer, parametric images were obtained, and statistical parametric mapping (SPM) analysis using a voxel-by-voxel statistical $t$ test was performed. Correlations between the cognitive and motor status and PET results were analyzed. Results: In YOPD patients, ${ }^{18} \mathrm{~F}$-fluoro-L-DOPA $\mathrm{K}_{\mathrm{i}}$ values were reduced to $68 \%$ (caudate) and $40 \%$ (putamen) of normal values $(P<0.0001)$. This decrease was symmetric and comparable for nonparkin and parkin patients. No correlation was found between the $K_{i}$ values and cognitive or motor status. ${ }^{11} \mathrm{C}-\mathrm{PE} 2 \mathrm{I} \mathrm{BP}_{\mathrm{DAT}}$ values in YOPD patients were decreased to $56 \%$ (caudate) and $41 \%$ (putamen) of normal values $(P<$ 0.0001 ) and did not differ between the 2 YOPD populations. The mean ${ }^{11} \mathrm{C}$-raclopride $\mathrm{BP}_{\mathrm{D} 2}$ values were reduced to $72 \%$ (caudate) and $84 \%$ (putamen) of the normal values $(P<0.02)$ and did not differ between nonparkin and parkin patients. SPM analyses showed in patients an additional decrease of ${ }^{11} \mathrm{C}$-raclopride in the frontal cortex and a decrease of ${ }^{18} \mathrm{~F}$-fluoro-L-DOPA and

Received Feb. 23, 2009; revision accepted Apr. 13, 2009.

For correspondence or reprints contact: Maria João Ribeiro, Service Hospitalier Frédéric Joliot, I2BM/DSV, CEA, 4, Place du Général Leclerc, F-91406 Orsay, France.

E-mail: maria-joao.ribeiro@cea.fr

COPYRIGHT @ 2009 by the Society of Nuclear Medicine, Inc.
${ }^{11} \mathrm{C}-\mathrm{PE} 2 \mathrm{I}$ uptake in the substantia nigra bilaterally $(P<0.05$, false-discovery rate-corrected). Conclusion: Carriers of parkin mutations are indistinguishable on PET markers of dopaminergic dysfunction from other YOPD patients with long disease duration.

Key Words: Parkinson; parkin gene; PET; ${ }^{18} \mathrm{~F}$-fluoro-L-DOPA; ${ }^{11} \mathrm{C}-\mathrm{PE} 2 \mathrm{I} ;{ }^{11} \mathrm{C}$-raclopride

J Nucl Med 2009; 50:1244-1250

DOI: 10.2967/jnumed.109.063529

$\mathbf{P}$ arkinson disease (PD) is clinically and genetically heterogeneous. Autosomal recessive young-onset PD (YOPD) corresponds in most families to mutations in the parkin gene located on chromosome $6 \mathrm{q}$ (1). Mutations are present in about $50 \%$ of all individuals with early onset $(<45 \mathrm{y})$ autosomal recessive parkinsonism (2). Mutations in the ubiquitin ligase parkin induce the accumulation of proteins in the endoplasmic reticulum, which participates in the degeneration of dopaminergic neurons (3). Parkin-linked PD gives rise to a broad range of phenotypes but generally has a slow clinical course, an excellent response to levodopa with early-onset dyskinesia, and no dementia $(4,5)$. These patients have a selective loss of pigmented neurons in the substantia nigra and locus coeruleus and, in most cases, no Lewy bodies (6-8).

PET studies performed in carriers of parkin mutations have shown a marked reduction of striatal ${ }^{18} \mathrm{~F}$-fluoro-L3,4-dihydroxyphenylalanine ( ${ }^{18}$ F-fluoro-L-DOPA) uptake, which predominated in both putamen and seemed more symmetric than in sporadic disease (9-15). However, no 
correlation has been provided between motor or cognitive status of YOPD patients and the extent of dopaminergic lesions measured with functional imaging.

The slower disease progression and sustained L-DOPA responsiveness in parkin patients might be related to compensatory mechanisms such as an overexpression of dopaminergic $\mathrm{D}_{2}$ receptors. However, previous studies suggested that $D_{2}$ binding was reduced in treated patients with parkin mutation $(11,16,17)$, this reduction being more severe than that in other YOPD subjects (16).

In idiopathic PD, the loss of dopaminergic synapses might be partially compensated for by increased dopamine metabolism in the surviving terminals. Thus, ${ }^{18} \mathrm{~F}$-fluoro-LDOPA uptake might overestimate the number of remaining dopaminergic terminals in PD patients $(18,19)$. Therefore, ligands binding to the presynaptic membrane dopamine transporter (DAT) might better reflect the density of dopaminergic nerve terminals $(19,20)$. Such comparison of 2 presynaptic dopamine tracers has never been performed in YOPD and could help to disclose dopaminergic presynaptic compensatory mechanisms in this population.

The aims of the present study were to determine whether PET using ${ }^{18} \mathrm{~F}$-fluoro-L-DOPA, ${ }^{11} \mathrm{C}$-PE2I (a radioligand of the presynaptic plasma membrane DAT), and ${ }^{11} \mathrm{C}$-raclopride (a $\mathrm{D}_{2}$ dopamine receptor antagonist) may help to differentiate YOPD patients with and without parkin mutation; to assess whether parkin patients, compared with nonparkin patients, harbor compensatory mechanisms that would explain the slow disease progression and relatively benign evolution, either at the presynaptic (by comparing ${ }^{18} \mathrm{~F}$-fluoro-L-DOPA and ${ }^{11} \mathrm{C}$-PE2I results) or at the postsynaptic level (by analyzing the $\mathrm{D}_{2}$ receptor density); and to look for correlations between PET data and clinical and neuropsychologic characteristics of the patients.

\section{MATERIALS AND METHODS}

\section{Patients}

A total of 35 patients (mean age $\pm \mathrm{SD}, 49 \pm 7 \mathrm{y} ; 15$ women, 20 men) with sporadic or familial early-onset $(<45$ y) PD (Table 1$)$, fulfilling the Parkinson's Brain Bank criteria for PD, were selected (21). The severity of the motor symptoms (as assessed by the Unified PD Rating Scale [UPDRS] motor score) was similar in both groups; at the time of the study, no statistically significant asymmetry of motor signs was identified, and disease always started on 1 hemibody. All the patients were chronically treated by a combination of levodopa and dopamine agonists but at a lower dose in patients carrying parkin mutations (Table 1). Eighteen patients were studied in Orsay, France, and 17 in Lyon, France. Sixteen patients were found to carry a homozygous $(n=3)$, a compound heterozygous $(n=11)$, or a heterozygous $(n=2)$ parkin mutation; 19 patients had no parkin mutation. The G2019S mutation of the LRRK2 gene and mutations of the DJ-1 and Pink1 genes were absent in all patients.

Neuropsychologic and psychiatric tests such as frontal score, lexical fluency (category and literal), and Montgomery-Asberg Depression Rating Scale (MADRS) (Table 1) were performed while the patients received their usual treatment and have been
TABLE 1. Characteristics of YOPD Populations (33

Patients Included in Final Analysis)

\begin{tabular}{|c|c|c|c|}
\hline Characteristic & $\begin{array}{l}\text { Nonparkin } \\
\text { patients } \\
(n=19)\end{array}$ & $\begin{array}{l}\text { Parkin } \\
\text { patients } \\
(n=14)\end{array}$ & $P$ \\
\hline Age (y) & $48.1 \pm 8.2$ & $50.5 \pm 6.3$ & 0.35 \\
\hline $\begin{array}{l}\text { Mean age at } \\
\text { onset (y) }\end{array}$ & $35.8 \pm 5.1$ & $31.0 \pm 8.4$ & 0.065 \\
\hline Disease duration $(\mathrm{y})$ & $12.1 \pm 7.0$ & $19.8 \pm 7.0$ & 0.0013 \\
\hline $\begin{array}{l}\text { Hoehn and Yahr } \\
\text { stage (off) }\end{array}$ & $2.9 \pm 0.8$ & $2.5 \pm 0.8$ & 0.37 \\
\hline $\begin{array}{l}\text { UPRDS } 3 \text { score } \\
\text { (off) }\end{array}$ & $39.7 \pm 16.1$ & $30.3 \pm 16.3$ & 0.11 \\
\hline $\begin{array}{l}\text { Frontal score } \\
\text { (/60) }\end{array}$ & $55.1 \pm 5.0$ & $53.6 \pm 6.0$ & 0.66 \\
\hline \multicolumn{4}{|l|}{ Lexical fluency } \\
\hline Category & $21.2 \pm 5.9$ & $20.5 \pm 6.3$ & 0.82 \\
\hline Literal & $9.6 \pm 1.0$ & $9.1 \pm 1.6$ & 0.39 \\
\hline MADRS & $13.2 \pm 7.8$ & $7.6 \pm 6.8$ & 0.035 \\
\hline $\begin{array}{l}\text { Levodopa } \\
\quad \text { equivalents }(\mathrm{mg} / \mathrm{d})\end{array}$ & $1,187.1 \pm 444.2$ & $710.4 \pm 504.3$ & 0.0053 \\
\hline
\end{tabular}

detailed previously (22). The severity of motor symptoms was determined using the UPDRS motor score, with the patient taking or not taking medication. The best-on state was determined after the administration of a supraliminal dose of levodopa (50 mg higher than the usual morning dose).

From these 35 YOPD patients, 18 were examined with ${ }^{18}$ F-fluoro-L-DOPA and ${ }^{11} \mathrm{C}$-PE2I (Orsay) and 12 with ${ }^{18} \mathrm{~F}$ fluoro-L-DOPA and ${ }^{11} \mathrm{C}$-raclopride (Lyon). Because of technical problems, 4 patients were scanned only with ${ }^{18} \mathrm{~F}$-fluoro-L-DOPA and 1 only with ${ }^{11} \mathrm{C}$-raclopride (Lyon). Nine patients without parkin mutation and 7 with parkin mutations scanned with ${ }^{11} \mathrm{C}$ PE2I were included in the final analysis. Two patients with heterozygous parkin mutation were also studied using this radiotracer, but they were excluded from the analysis. We evaluated 5 parkin and 8 nonparkin patients using ${ }^{11} \mathrm{C}$-raclopride. YOPD patients were compared with healthy controls, scanned with ${ }^{18} \mathrm{~F}$ fluoro-L-DOPA $(n=37$; age, $45 \pm 12 \mathrm{y}),{ }^{11} \mathrm{C}-\mathrm{PE} 2 \mathrm{I}(n=11$; age, $46 \pm 7 \mathrm{y}$ ), or ${ }^{11} \mathrm{C}$-raclopride $(n=8$; age, $56 \pm 9 \mathrm{y})$. None of the healthy volunteers had any psychiatric or neurologic disease, and all had normal brain MRI results. None of the healthy volunteers was taking medication. The patients scanned here were part of a clinical protocol including 44 YOPD patients (22). The study was approved by local Ethics Committees, and all subjects gave their written informed consent after the procedure had been fully explained.

\section{PET Acquisition}

All PET studies were performed after withdrawal of antiparkinsonian medication for at least $12 \mathrm{~h}$. PET examinations were performed using 2 identical ECAT EXACT-HR+ tomographs (Siemens Medical Solutions), which collect 63 simultaneous 2.4mm-thick slices (in-plane resolution, $4.3 \mathrm{~mm}$ ). Subjects were positioned in the tomograph using a 3-dimensional laser alignment, and a thermoplastic mask was molded to each patient's face to restrain head movements. Tissue attenuation was measured with three ${ }^{68} \mathrm{Ge}$ rod sources. Datasets, acquired in 3-dimensional mode, 
were reconstructed using a Hanning apodization window $(0.5$ cycles/pixel cutoff); radial and axial filters provided an image resolution of $6.6 \mathrm{~mm}$ in the 3 directions.

For ${ }^{18}$ F-fluoro-L-DOPA PET studies, all subjects received 100 $\mathrm{mg}$ of carbidopa or $50 \mathrm{mg}$ of benzeraside orally, $1 \mathrm{~h}$ before the intravenous injection of the radiotracer $(146 \pm 26 \mathrm{MBq})$; images were acquired over $90 \mathrm{~min} .{ }^{11} \mathrm{C}$-PE2I images were acquired over $60 \mathrm{~min}$ after the intravenous injection of the radiotracer $(269 \pm 54$ $\mathrm{MBq}$; specific activity, $32 \pm 17 \mathrm{GBq} / \mu \mathrm{mol})$. Images were acquired over $60 \mathrm{~min}$ after the intravenous injection of ${ }^{11} \mathrm{C}$ raclopride (208 $\pm 32 \mathrm{MBq}$; specific activity, $70 \pm 48 \mathrm{GBq} / \mu \mathrm{mol})$.

\section{Data Analysis}

The images collected between 30 and 90 min after ${ }^{18} \mathrm{~F}$-fluoro-LDOPA injection and between 30 and $60 \mathrm{~min}$ after ${ }^{11} \mathrm{C}$-PE2I or ${ }^{11} \mathrm{C}$-raclopride injection were summed to create integrated images. These images were used to define circular regions of interest (ROIs) in the striata and the occipital lobe or the cerebellum in 5-8 contiguous planes, in which these structures are visualized as described previously (19). The mean activity concentration values in the ROI for the left and right caudate nuclei and putamina, occipital cortex, or cerebellum were calculated to obtain regional time-activity curves. The ${ }^{18}$ F-fluoro-L-DOPA uptake constant values $\left(\mathrm{K}_{\mathrm{i}}\right)$ were determined using a multiple-time graphical analysis, with the occipital activity as a nonspecific input function (23). The specific uptake of ${ }^{11} \mathrm{C}$-PE2I allowing the calculation of the striatal binding potential $\left(\mathrm{BP}_{\mathrm{DAT}}\right)$ values of this radioligand was obtained with the Logan graphical analysis (24). For ${ }^{11} \mathrm{C}$ raclopride, we used the graphical analysis described by Lammertsma et al. (25) to calculate the striatal binding potential $\left(\mathrm{BP}_{\mathrm{D} 2}\right)$. For ${ }^{11} \mathrm{C}$-raclopride and ${ }^{11} \mathrm{C}$-PE2I, we used cerebellum activity as a nonspecific input function. For each radiotracer, the caudate-to-putamen ratio was calculated in the more- and lessaffected hemispheres.

Parametric images were also obtained using the nonspecific activity concentration as an input function and PMOD software (PMOD Technologies). Parametric images were normalized onto Talairach stereotactic space with statistical parametric mapping (SPM) software (SPM5; Wellcome Department of Cognitive Neurology), using images obtained by summing all dynamic frames of each acquisition to identify the transformation parameters. The scans were flipped so that for all patients the most- and least-affected sides were aligned, and images were smoothed with an isotropic gaussian kernel of $6 \mathrm{~mm}$ in full width half maximum. The SPM comparisons of parametric images between the different groups of patients and controls were performed voxel by voxel using a $t$ test analysis with a significance threshold set at a level of at least $P$ less than 0.05 , false-discovery rate (FDR)-corrected.

Patients with heterozygous parkin mutations were excluded from statistical analysis. The nonparkin and parkin patients were compared for $\mathrm{K}_{\mathrm{i}}, \mathrm{BP}_{\mathrm{DAT}}$, and $\mathrm{BP}_{\mathrm{D} 2}$ values in more- and lessaffected caudate and putamen using a Kruskal-Wallis test. The more- and less-affected sides were determined on a clinical basis using UPDRS part III scores and the initially affected hemibody.

In addition, the $\mathrm{K}_{\mathrm{i}}, \mathrm{BP}_{\mathrm{DAT}}$, and $\mathrm{BP}_{\mathrm{D} 2}$ values in each patient were normalized to corresponding mean values obtained in controls.

To study the correlations between $K_{i}$ values and clinical variables (UPDRS motor score on and off, MADRS, lexical fluency, and frontal score), Spearman correlation coefficients were computed.

\section{RESULTS}

\section{${ }^{18}$ F-Fluoro-L-DOPA}

In YOPD patients, $\mathrm{K}_{\mathrm{i}}$ values, averaged over both hemispheres, were reduced to $67 \% \pm 21 \%$ of control values in the caudate and $39 \% \pm 11 \%$ of control values in the putamen (Table 2; Fig. 1A). No significant difference between parkin and nonparkin YOPD patients for ${ }^{18} \mathrm{~F}-$ fluoro-L-DOPA uptake reductions in the striatum $(P=0.17$ for caudate and $P=0.52$ for putamen) was observed (Fig. 2). The asymmetry of $\mathrm{K}_{\mathrm{i}}$ values, determined according to the clinically more affected hemibody, was not statistically significant in either group of patients. The caudate-to-putamen ratios were all greater than 1.66 (Table 3). No correlation was found between ${ }^{18} \mathrm{~F}$-fluoro-L-DOPA $\mathrm{K}_{\mathrm{i}}$ values and the clinical scores.

When compared with controls using SPM $(P<0.05$, FDRcorrected), all YOPD patients had a rather symmetric

\section{TABLE 2. ${ }^{18}$ F-Fluoro-L-DOPA $K_{\mathrm{i}},{ }^{11} \mathrm{C}$-PE2I BP $\mathrm{BAT}$, and ${ }^{11} \mathrm{C}$-Raclopride $\mathrm{BP}_{\mathrm{D} 2}$ Values in Different Study Groups}

\begin{tabular}{|c|c|c|c|c|c|c|c|}
\hline \multirow[b]{3}{*}{ Radiotracer } & \multicolumn{7}{|c|}{ Study group } \\
\hline & \multirow[b]{2}{*}{ Controls, mean } & \multicolumn{3}{|c|}{ Nonparkin patients } & \multicolumn{3}{|c|}{ Parkin patients } \\
\hline & & Mean & Less affected & More affected & Mean & Less affected & More affected \\
\hline \multicolumn{8}{|c|}{${ }^{18}$ F-fluoro-L-DOPA $\left(K_{i}\right)$} \\
\hline Caudate & $0.0123 \pm 0.0012$ & $0.0087 \pm 0.0026$ & $0.0091 \pm 0.0030$ & $0.0083 \pm 0.0025$ & $0.0076 \pm 0.0023$ & $0.0077 \pm 0.0025$ & $0.0075 \pm 0.0024$ \\
\hline Putamen & $0.0123 \pm 0.0011$ & $0.0049 \pm 0.0015$ & $0.0051 \pm 0.0018$ & $0.0047 \pm 0.0016$ & $0.0046 \pm 0.0012$ & $0.0046 \pm 0.0013$ & $0.0044 \pm 0.0011$ \\
\hline \multicolumn{8}{|c|}{${ }^{11} \mathrm{C}-\mathrm{PE} 2 \mathrm{I}(\mathrm{BP}$ DAT) } \\
\hline Caudate & $4.52 \pm 0.46$ & $2.66 \pm 0.69$ & $2.75 \pm 0.67$ & $2.57 \pm 0.73$ & $2.39 \pm 0.22$ & $2.41 \pm 0.25$ & $2.36 \pm 0.22$ \\
\hline Putamen & $4.42 \pm 0.43$ & $1.85 \pm 0.42$ & $1.93 \pm 0.47$ & $1.76 \pm 0.38$ & $1.78 \pm 0.14$ & $1.77 \pm 0.14$ & $1.79 \pm 0.14$ \\
\hline \multicolumn{8}{|c|}{${ }^{11} \mathrm{C}$-raclopride $\left(\mathrm{BP}_{\mathrm{D} 2}\right)$} \\
\hline Caudate & $2.72 \pm 0.24$ & $2.02 \pm 0.30$ & $2.06 \pm 0.29$ & $1.98 \pm 0.33$ & $1.87 \pm 0.19$ & $1.91 \pm 0.17$ & $1.83 \pm 0.17$ \\
\hline Putamen & $3.02 \pm 0.40$ & $2.63 \pm 0.47$ & $2.60 \pm 0.47$ & $2.65 \pm 0.48$ & $2.33 \pm 0.14$ & $2.35 \pm 0.13$ & $2.32 \pm 0.20$ \\
\hline \multicolumn{8}{|c|}{$\begin{array}{l}\text { All values are mean } \pm \text { SD. Less- and more-affected sides were determined on clinical basis. Only } 33 \text { Parkinson patients were } \\
\text { included in final analysis. No significant differences were observed for } \mathrm{K}_{\mathrm{i}}, \mathrm{BP}_{\mathrm{DAT}} \text {, and } \mathrm{BP}_{\mathrm{D} 2} \text { between nonparkin and parkin patients. For } \\
{ }^{18} \mathrm{~F} \text {-fluoro-L-DOPA, } 37 \text { controls, } 18 \text { nonparkin patients, and } 14 \text { parkin patients were studied; for }{ }^{11} \mathrm{C}-\mathrm{PE} 2 \mathrm{I}\left(\mathrm{BP} \mathrm{P}_{\mathrm{DAT}}\right), 11 \mathrm{controls,} 9 \\
\left.\text { nonparkin patients, and } 7 \text { parkin patients were studied; and for }{ }^{11} \mathrm{C} \text {-raclopride (BP } \mathrm{B}_{\mathrm{D} 2}\right), 8 \text { controls, } 8 \text { nonparkin patients, and } 5 \text { parkin } \\
\text { patients were studied. }\end{array}$} \\
\hline
\end{tabular}




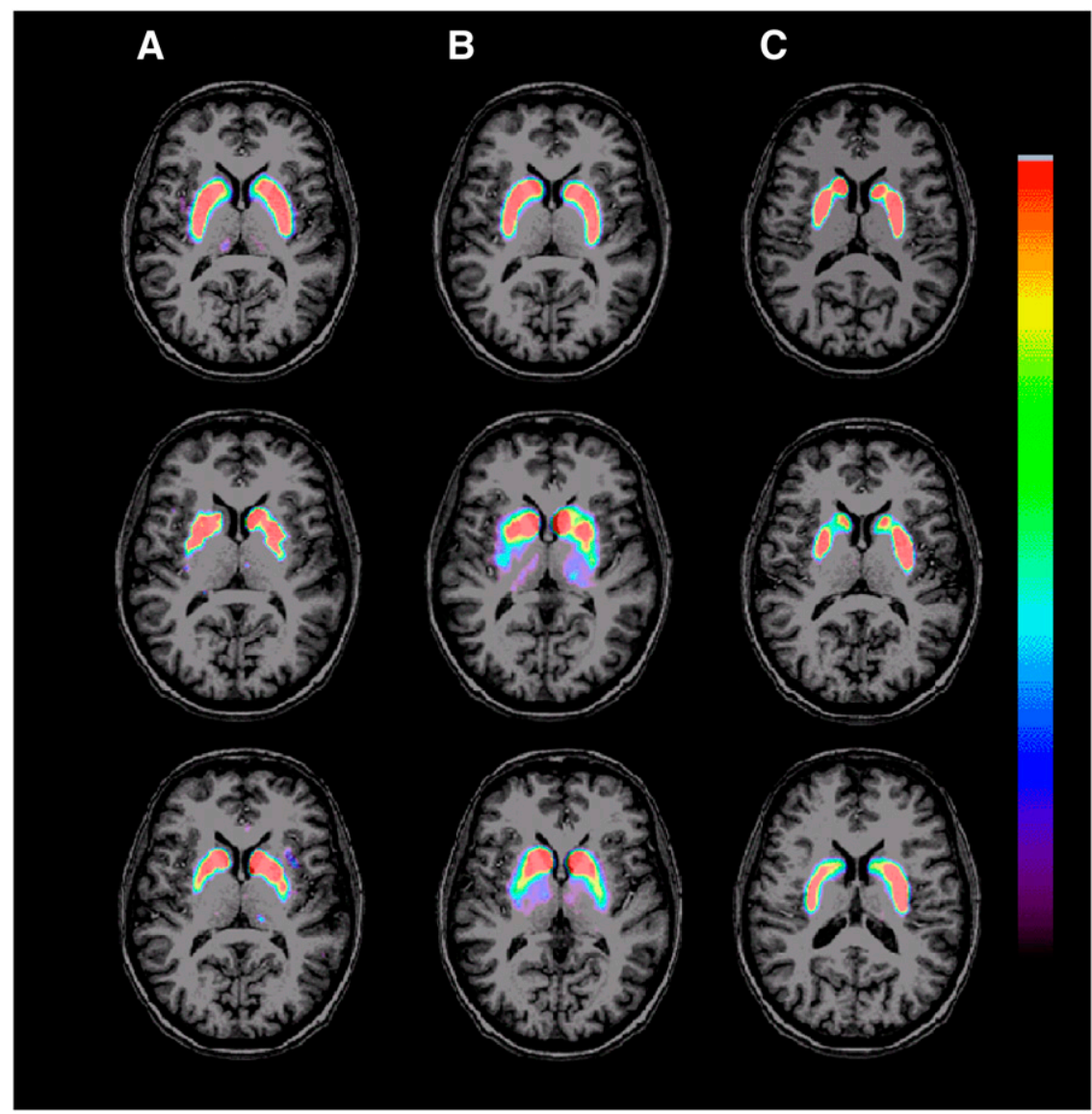

FIGURE 1. Images of ${ }^{18} \mathrm{~F}$-fluoroL-DOPA (A), ${ }^{11} \mathrm{C}-P E 2$ I (B), and ${ }^{11} \mathrm{C}$ raclopride (C) in control (top), nonparkin patient (middle), and parkin patient (bottom). decrease of ${ }^{18} \mathrm{~F}$-fluoro-L-DOPA uptake in the putamen (mostaffected side, 761 voxels; least-affected side, 651 voxels; 1 voxel, $8 \mathrm{~mm}^{3}$ ) and in the substantia nigra (211 voxels) (Fig. 3A). No statistically significant difference between parkin and nonparkin patients using SPM was found.

No correlation was found between the $\mathrm{K}_{\mathrm{i}}$ values and cognitive or motor scores; for all analysis $P$ was greater than 0.5 .

There was no major difference between the 2 groups in terms of general cognitive efficiency. Psychiatric manifestations (depression) did not differ between the 2 groups of patients.

\section{${ }^{11} \mathrm{C}-\mathrm{PE} 2 \mid$}

The mean values of $\mathrm{BP}_{\mathrm{DAT}}$ obtained in all YOPD patients were significantly reduced $(P<0.0001)$ to $56 \% \pm 11 \%$ of control values in the caudate and to $41 \% \pm 7 \%$ of control values in the putamen and were symmetric in all groups of patients (Table 2; Fig. 1B). The $\mathrm{BP}_{\mathrm{DAT}}$ values did not differ between parkin and nonparkin patients (Fig. 2). The caudateto-putamen ratios were all greater than 1.33 (Table 3).

The SPM analysis of all YOPD patients, compared with the controls, revealed a significant and symmetric decrease $\left(P<0.05\right.$, FDR-corrected) of ${ }^{11} \mathrm{C}-\mathrm{PE} 2 \mathrm{I}$ uptake in the putamen (most-affected side, 2,710 voxels, and leastaffected side, 2,870 voxels) and in the substantia nigra (118 voxels) (Fig. 3B). SPM comparisons did not reveal any difference between parkin and nonparkin groups.

\section{${ }^{11} \mathrm{C}-$ Raclopride}

The mean $\mathrm{BP}_{\mathrm{D} 2}$ values calculated for $\mathrm{YOPD}$ in the caudate $(1.96 \pm 0.26)$ and putamen $(2.51 \pm 0.40)$ were significantly reduced, compared with control values (caudate, $2.72 \pm 0.24, P<0.0002$; putamen, $3.02 \pm 0.40, P<$ 0.02). $\mathrm{BP}_{\mathrm{D} 2}$ did not differ significantly between nonparkin and parkin patients $(P=0.38)$ (Tables 2 and 3; Fig. 1C). For both patient groups, the ${ }^{11} \mathrm{C}$-raclopride $\mathrm{BP}_{\mathrm{D} 2}$ values did not differ between the more- and less-affected sides (Tables 2 and 3); $\mathrm{BP}_{\mathrm{D} 2}$ decrease was more pronounced in the caudate than in the putamen (Table 3 ).

The SPM analysis revealed a significant decrease $(P<$ 0.05 , FDR-corrected) of ${ }^{11} \mathrm{C}$-raclopride uptake in the YOPD patients, compared with controls, mainly in the caudate nuclei (most-affected side, 855 voxels, and leastaffected side, 580 voxels) and in the frontal cortex (Talairach coordinates, 18, -28, 57 [109 voxels]; 36, 5, 29 [340 voxels]; 22, 10, 35 [158 voxels]; $-16,-17,45$ [149 voxels]; and $-30,45,-2$ [133 voxels]) (Fig. 3C). SPM did not reveal any difference between parkin and nonparkin patients.

\section{DISCUSSION}

We report the largest series, to our knowledge, of YOPD patients studied with PET, and contrary to most of the previous studies, we excluded DJ-1 and Pink 1 mutations; 


\begin{tabular}{|c|c|c|c|c|c|}
\hline $\min ^{-1}$ & Caudate $\mathrm{K}_{\mathrm{i}}$ & * & Caudate $\mathrm{BP}_{\mathrm{DAT}}$ & * & Caudate $\mathrm{BP}_{\mathrm{R} 2}$ \\
\hline 0.016 & • & & $:$ & 3.0 & $\bullet$ \\
\hline 0.014 & 8 & & $?$ & & 8 \\
\hline 0.012 & 8 & 4.0 & 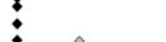 & 2.0 & 8 \\
\hline 0.010 & 8 & 30 & 8 & 2.0 & $\therefore$ \\
\hline 0.008 & 8 & & $\therefore$ & 1.5 & ${ }^{\circ}$ \\
\hline 0.006 & 8 & 2.0 & 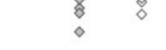 & $1.0-$ & \\
\hline 0.004 & $\diamond$ & 1.0 & & 05 & \\
\hline 0.002 & & & & & \\
\hline ] & & $0.0^{]}$ & & $0.0]$ & \\
\hline $\begin{array}{c}\min ^{-1} \\
0.016\end{array}$ & Putamen $\mathrm{K}_{\mathrm{i}}$ & $\begin{array}{c}* \\
6.0\end{array}$ & Putamen $\mathrm{BP}_{\mathrm{DAT}}$ & $4.0^{*}$ & Putamen $\mathrm{BP}_{\mathrm{R} 2}$ \\
\hline 0.014 & 8 & 5.0 & : & 3.5 & ; \\
\hline 0.012 & & & 8 & 3.0 & $\bullet$ \\
\hline 0.010 & 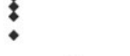 & 4.0 & - & 2.5 & $\dot{0}$ \\
\hline 0.008 & $\diamond$ & 3.0 & & 2.0 & 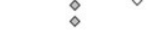 \\
\hline 0.006 & $\because$ & 20 & $:$ & 1.5 & \\
\hline 0.004 & 8 & & 8 & 1.0 & \\
\hline 0.002 & $\gamma$ & 1.0 & & $0.5-$ & \\
\hline ل 0.000 & & $0.0]$ & & $0.0]$ & \\
\hline
\end{tabular}

FIGURE 2. $\mathrm{K}_{\mathrm{i}}, \mathrm{BP}_{\mathrm{DAT}}$, and $\mathrm{BP}_{\mathrm{D} 2}$ individual caudate and putamen mean values. Control (first column), nonparkin patients (middle column), and parkin patients (last column). ${ }^{\star} \mathrm{BP}$ without units.

this exclusion does not rule out the presence of other mutations but eliminates the known other recessive forms of PD. Both SPM and ROI analyses revealed a significant but symmetric reduction of presynaptic dopaminergic markers in the nigra and striatum of both groups of PD patients; this reduction predominated in the putamen but was not different between parkin and nonparkin patients. $\mathrm{D}_{2}$ binding was mainly reduced in the caudate nucleus in these treated patients, and again no statistical difference between parkin and nonparkin patients was observed.

For safety reasons, it was not possible to scan the same patients 3 times, and although all the patients except 1 had undergone ${ }^{18} \mathrm{~F}$-fluoro-L-DOPA PET, a portion of these patients underwent ${ }^{11} \mathrm{C}$-PE2I and others were scanned with ${ }^{11} \mathrm{C}$ - raclopride. Overall, more nonparkin patients were studied, whatever the tracer used. However, these differences could have biased our results because the proportion of patients scanned with each tracer was grossly similar in each group.

In both YOPD groups, the reduction of presynaptic markers of the dopaminergic system (i.e., ${ }^{18} \mathrm{~F}$-fluoroL-DOPA and ${ }^{11} \mathrm{C}$-PE2I) reveals a pattern that is in line with previous studies $(9,13,16,26-28)$. Indeed, there is a marked anteroposterior gradient, with all caudate-to-putamen ratios higher than 1.33 , an observation similar to that made in sporadic PD. However, the peculiarity in this cohort is the symmetric reduction of these markers, which is obvious using ROI and SPM analyses and any of the tracers. This symmetric reduction fits well with the absence of significant clinical asymmetry of the motor signs at this stage of the disease, despite an asymmetry at disease onset. This symmetry, occasionally reported in previous studies (13), is present in both nonparkin and parkin patients, suggeting that the symmetry is related to the genetic origin of the disease in these groups. However, this question of symmetry or asymmetry has to be taken with caution because, at this stage of the disease, the dopaminergic cell loss is major and may reach a floor at which a much larger population would be needed before differences in tracer uptake between the 2 sides would become evident. Although disease duration is longer in parkin $(20 \mathrm{y}$, on average) than in nonparkin (12 y) patients and UPDRS motors scores are higher in the latter group $(\sim 40)$ than in parkin subjects $(\sim 30)$, we found no difference of presynaptic dopaminergic markers between parkin and nonparkin patients. This result suggests that for the same degree of dopaminergic denervation, the disease is less severe and progresses more slowly in patients with a parkin mutation than in patients with an unknown mutation. Interestingly, this discrepancy is not related to a difference in presynaptic compensatory mechanisms in the 2 groups of YOPD. Indeed, previous studies revealed that early in the course of late-onset PD there is an overactivity of L-amino acid decarboxylase in the surviving dopaminergic terminals to compensate for the loss of dopaminergic neurons, which leads to an underestimation of the importance of dopaminergic degeneration by ${ }^{18} \mathrm{~F}$-fluoro-L-DOPA, and DAT binding is more sensitive to dopaminergic cell loss $(18,19)$. Here, the reduction of ${ }^{18} \mathrm{~F}$-fluoro-L-DOPA and $\mathrm{BP}_{\mathrm{DAT}}$ is comparable for the 2 groups of YOPD, discarding the

\section{TABLE 3. Caudate-to-Putamen Ratios Obtained in Each Group of Patients and Controls}

\begin{tabular}{lcccccc} 
& \multicolumn{2}{c}{ Nonparkin patients } & & \multicolumn{2}{c}{ Parkin patients } & Control, average over \\
\cline { 2 - 3 } Parameter & Less affected & More affected & & Less affected & More affected & $1.00 \pm 0.10$ \\
both hemispheres
\end{tabular}


A
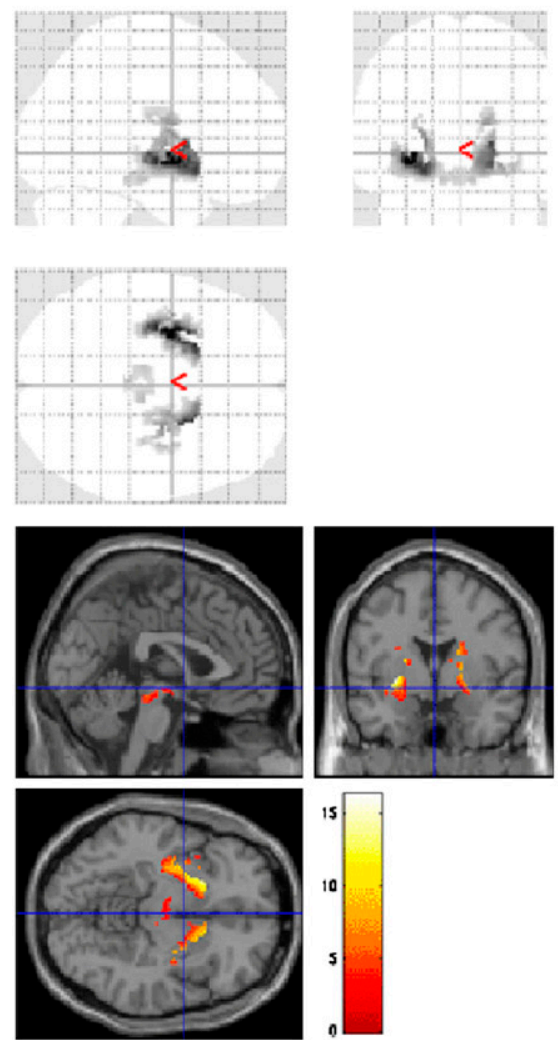

B
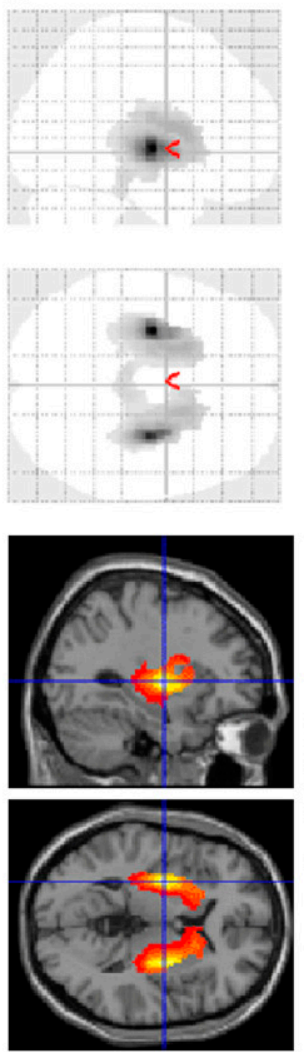
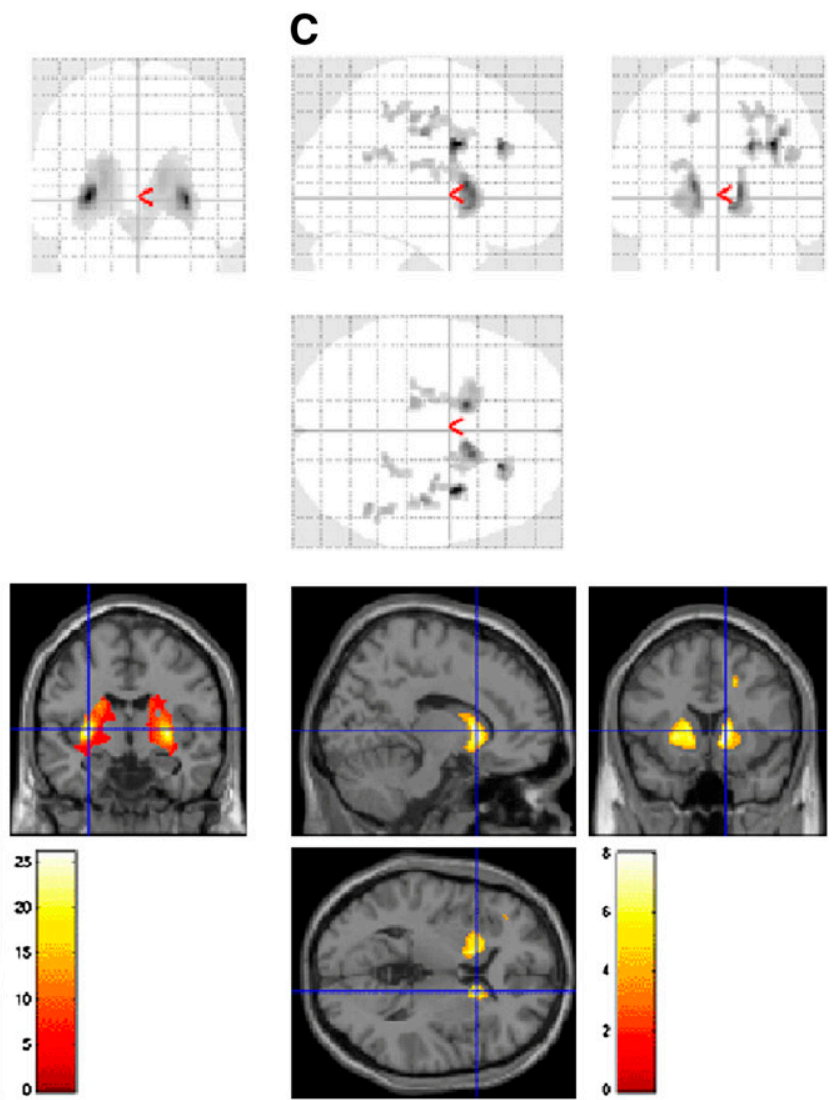

FIGURE 3. SPM showing significant $\left(P<0.05\right.$, FDR-corrected) decrease of ${ }^{18} \mathrm{~F}$-fluoro-L-DOPA (A), ${ }^{11} \mathrm{C}-\mathrm{PE} 2 \mathrm{I}$ (B), and ${ }^{11} \mathrm{C}-$ raclopride $(\mathrm{C})$ uptakes in YOPD patients, compared with controls. Decrease of ${ }^{18} \mathrm{~F}$-fluoro-L-DOPA and ${ }^{11} \mathrm{C}-\mathrm{PE} 2 \mathrm{I}$ uptake occurs in substantia nigra and striatum. For ${ }^{11} \mathrm{C}$-raclopride, decrease occurs mainly in caudate and frontal cortex.

likelihood of an increase of dopamine synthesis in parkin patients that would be responsible for less severe motor impairment of this group. Alternatively, extra-striatal changes in dopaminergic function might explain clinical differences. For example, in idiopathic PD, compared with in controls, increased ${ }^{18} \mathrm{~F}$-fluoro-L-DOPA uptake has been noted in several cortical regions and in the internal pallidum at disease onset $(29,30)$. However, SPM analysis found no extra-striatal difference of ${ }^{18} \mathrm{~F}$-fluoro-L-DOPA uptake or DAT binding between the 2 groups of YOPD.

Eventually, another possibility for compensatory mechanisms might involve the postsynaptic $\mathrm{D}_{2}$ receptors. In drug-naïve or early-stage PD patients, most PET studies using ${ }^{11} \mathrm{C}$-raclopride found an increased radioligand binding in the putamen, whereas binding is usually normal in the caudate nucleus (31-33). This result is considered as a compensatory dopaminergic receptor upregulation, which disappears in more advanced stages of the disease when patients are treated (34). A similar finding has been reported in drug-naïve parkin patients (17). Conversely, the same team found a significant reduction of ${ }^{11} \mathrm{C}$-raclopride $\mathrm{BP}$ in the striatum and thalamic and cortical areas in chronically treated parkin patients, compared with nonparkin YOPD (16). These authors suggested that such difference could be a direct consequence of parkin mutations or caused by a greater susceptibility to dopaminergic drug exposure (16).

However, in the present study the ${ }^{11} \mathrm{C}$-raclopride binding reduction was not statistically different in both YOPD populations: $\mathrm{BP}_{\mathrm{D} 2}$ values are lower in the parkin group by $9 \%$ of normal values in the putamen and $6 \%$ in the caudate, but this difference is not significant, suggesting that chronic exposure to dopaminergic drugs is responsible for a downregulation of dopamine receptors in PD independent of the genetic status of the patients (35). In addition, SPM analysis does not reveal any striatal or extra-striatal difference between the 2 groups for $\mathrm{D}_{2}$ binding. This might reflect a difference in the populations examined in the present study and in the study by Scherfler et al. (16), because the samples have similar size. This is further supported by the fact that the patients with parkin mutation in the study of Scherfler et al. (16) had a more severe UPDRS motor score than did the nonparkin ones, whereas the reverse is observed in our study. However, both studies suggest that the upregulation of $\mathrm{D}_{2}$ receptors is not the mechanism that reduces clinical disease severity in parkin patients, compared with other YOPD populations, at least at this stage of the disease, with the limitation 
represented by the effects of dopaminergic drugs on the dopamine receptor (35).

\section{CONCLUSION}

Our results show that despite a more symmetric dopaminergic cell loss, YOPD patients with long disease duration and under chronic dopaminergic treatment present similar features of ${ }^{18} \mathrm{~F}$-fluoro-L-DOPA uptake, DAT, and $\mathrm{D}_{2}$ binding in the striatum than do sporadic chronically treated late-onset PD patients, also with long disease duration. In addition, we did not find any specific pattern of presynaptic or postsynaptic markers of the dopaminergic system that would explain the fact that the parkin patients have a less severe clinical disease than YOPD patients without parkin gene mutation.

\section{ACKNOWLEDGMENTS}

We are grateful to the patients and families. We thank the radiochemists and nurses of the Service Hospitalier Frédéric Joliot, CERMEP, and Centre d'Investigation Clinique for their assistance. We acknowledge Céline Chamayou and Aurélie Funkiewiez for the collection of neuropsychologic data, Cécile Behar and Mircéa Polosan for psychiatric advice, Dr. Dirk Roeda and Dr. Claire Leroy for the critical reading of the manuscript, and the DNA and Cell Bank of the CRicm UMRS975 for sample preparation. This study was supported by INSERM/AP-HP (grant PCR02006-P011104).

\section{REFERENCES}

1. Kitada T, Asakawa S, Hattori N, et al. Mutations in the parkin gene cause autosomal recessive juvenile parkinsonism. Nature. 1998;392:605-608.

2. Periquet M, Latouche M, Lohmann E, et al. Parkin mutations are frequent in patients with isolated early-onset parkinsonism. Brain. 2003;126:1271-1278.

3. Hirsch C, Gauss R, Horn SC, Neuber O, Sommer T. The ubiquitylation machinery of the endoplasmic reticulum. Nature. 2009;458:453-460.

4. Lücking CB, Dürr A, Bonifati V, et al. Association between early-onset Parkinson's disease and mutations in the parkin gene. $N$ Engl J Med. 2000;342: 1560-1567.

5. Lohmann E, Periquet M, Bonifati V, et al. How much phenotypic variation can be attributed to parkin genotype? Ann Neurol. 2003;54:176-185.

6. Takahashi H, Ohama E, Suzuki S, et al. Familial juvenile parkinsonism: clinical and pathologic study in a family. Neurology. 1994;44:437-441.

7. van de Warrenburg BP, Lammens M, Lücking CB, et al. Clinical and pathologic abnormalities in a family with parkinsonism and parkin gene mutations. Neurology. 2001;56:555-557.

8. Sasaki S, Shirata A, Yamane K, Iwata M. Parkin-positive autosomal recessive juvenile parkinsonism with $\alpha$-synuclein-positive inclusions. Neurology. 2004;63: 678-682.

9. Broussolle E, Lücking CB, Ginovart N, Pollak P, Remy P, Dürr A. $\left[{ }^{18} \mathrm{~F}\right]$-dopa PET study in patients with juvenile-onset $\mathrm{PD}$ and parkin gene mutations. Neurology. 2000;55:877-879.

10. Pramstaller PP, Künig G, Leenders K, et al. Parkin mutations in a patient with hemiparkinsonism-hemiatrophy: a clinical-genetic and PET study. Neurology. 2002;58:808-810.

11. Hilker R, Klein C, Ghaemi M, et al. Positron emission tomographic analysis of the nigrostriatal dopaminergic system in familial parkinsonism associated with mutations in the parkin gene. Ann Neurol. 2001;49:367-376.

12. Hilker R, Klein $\mathrm{C}$, Hedrich $\mathrm{K}$, et al. The striatal dopaminergic deficit is dependent on the number of mutant alleles in a family with mutations in the parkin gene: evidence for enzymatic parkin function in humans. Neurosci Lett. 2002;323:50-54

13. Thobois S, Ribeiro MJ, Lohmann E, et al. Young-onset Parkinson disease with and without parkin gene mutations: a fluorodopa F 18 positron emission tomography study. Arch Neurol. 2003;60:713-718.

14. Khan NL, Scherfler C, Graham E, et al. Dopaminergic dysfunction in unrelated, asymptomatic carriers of a single parkin mutation. Neurology. 2005;64:134-136.

15. Binkofski F, Reetz K, Gaser C, et al. Morphometric fingerprint of asymptomatic parkin and PINK1 mutation carriers in the basal ganglia. Neurology. 2007;69: $842-850$.

16. Scherfler C, Khan NL, Pavese N, et al. Striatal and cortical pre- and postsynaptic dopaminergic dysfunction in sporadic parkin-linked parkinsonism. Brain. 2004; 127:1332-1342.

17. Scherfler C, Khan NL, Pavese N, et al. Upregulation of dopamine D2 receptors in dopaminergic drug-naïve patients with parkin gene mutations. Mov Disord. 2006;21:783-788.

18. Lee CS, Samii A, Sossi V, et al. In vivo positron emission tomographic evidence for compensatory changes in presynaptic dopaminergic nerve terminals in Parkinson's disease. Ann Neurol. 2000;47:493-503.

19. Ribeiro MJ, Vidailhet M, Loc'h C, et al. Dopaminergic function and dopamine transporter binding assessed with positron emission tomography in Parkinson disease. Arch Neurol. 2002;59:580-586.

20. Innis RB, Seibyl JP, Scanley BE, et al. Single photon emission computed tomographic imaging demonstrates loss of striatal dopamine transporters in Parkinson disease. Proc Natl Acad Sci USA. 1993;90:11965-11969.

21. Daniel SE, Lees AJ. Parkinson's Disease Society Brain Bank, London: overview and research. J Neural Transm Suppl. 1993;39:165-172.

22. Lohmann E, Thobois $\mathrm{S}$, Lesage $\mathrm{S}$, et al. A multidisciplinary study of early-onset PD patients with and without parkin mutations. Neurology. 2009;72:110-116.

23. Patlak CS, Blasberg RG. Graphical evaluation of blood-to-brain transfer constants from multiple-time uptake data: generalizations. J Cereb Blood Flow Metab. 1985;5:584-590.

24. Logan J, Fowler JS, Volkow ND, et al. Graphical analysis of reversible radioligand binding from time-activity measurements applied to $\left[\mathrm{N}^{11} \mathrm{C}\right.$-methyl](-)-cocaine PET studies in human subjects. J Cereb Blood Flow Metab. 1990; 10:740-747.

25. Lammertsma AA, Bench CJ, Hume SP, et al. Comparison of methods for analysis of clinical $\left[{ }^{11} \mathrm{C}\right]$-raclopride studies. J Cereb Blood Flow Metab. 1996; $16: 42-52$.

26. Portman AT, Giladi N, Leenders KL, et al. The nigrostriatal dopaminergic system in familial early onset parkinsonism with parkin mutations. Neurology. 2001;56:1759-1762.

27. Varrone A, Pellecchia MT, Amboni M, et al. Imaging of dopaminergic dysfunction with $\left[{ }^{123}\right.$ I] FP-CIT SPECT in early-onset parkin disease. Neurology. 2004;63:2097-2103.

28. Shyu WC, Lin SZ, Chiang MF, et al. Early-onset Parkinson's disease in a Chinese population: ${ }^{99 \mathrm{~m}}$ Tc-TRODAT-1 SPECT, parkin gene analysis and clinical study. Parkinsonism Relat Disord. 2005;11:173-180.

29. Rakshi JS, Uema T, Ito K, et al. Frontal, midbrain and striatal dopaminergic function in early and advanced Parkinson's disease: a 3D $\left[{ }^{18} \mathrm{~F}\right]$ dopa-PET study. Brain. 1999;122:1637-1650.

30. Whone AL, Moore RY, Piccini PP, Brooks DJ. Plasticity of the nigropallidal pathway in Parkinson's disease. Ann Neurol. 2003;53:206-213.

31. Rinne UK, Laihinen A, Rinne JO, Någren K, Bergman J, Ruotsalainen U. Positron emission tomography demonstrates dopamine D2 receptor supersensitivity in the striatum of patients with early Parkinson's disease. Mov Disord. 1990;5:55-59.

32. Rinne JO, Laihinen A, Ruottinen H, et al. Increased density of dopamine D2 receptors in the putamen, but not in the caudate nucleus in early Parkinson's disease: a PET study with $\left[{ }^{11}\right.$ C]-raclopride. J Neurol Sci. 1995;132:156-161.

33. Brooks DJ, Ibanez V, Sawle GV, et al. Striatal D2 receptor status in patients with Parkinson's disease, striatonigral degeneration, and progressive supranuclear palsy, measured with ${ }^{11} \mathrm{C}$-raclopride and positron emission tomography. Ann Neurol. 1992;31:184-192.

34. Antonini A, Schwarz J, Oertel WH, Pogarell O, Leenders KL. Long-term changes of striatal dopamine D2 receptors in patients with Parkinson's disease: a study with positron emission tomography and $\left[{ }^{11} \mathrm{C}\right]$-raclopride. Mov Disord. 1997; 12:33-38.

35. Thobois S, Vingerhoets F, Fraix V, et al. Role of dopaminergic treatment in dopamine receptor down-regulation in advanced Parkinson disease: a positron emission tomographic study. Arch Neurol. 2004;61:1705-1709. 